\title{
A PARTICIPAÇÃO DA FAMÍLIA NO TRATAMENTO DOS TRANSTORNOS ALIMENTARES
}

\author{
Laura Vilela e Souza* \\ Manoel Antonio dos Santos ${ }^{\#}$
}

\begin{abstract}
RESUMO. O objetivo deste estudo foi compreender os sentidos da participação da família no tratamento produzidos em um grupo de apoio aos familiares de pessoas diagnosticadas com anorexia e bulimia. Participaram familiares atendidos no contexto de um serviço especializado. O corpus foi constituído pelos registros audiogravados de sessão de grupo, nos quais se buscou delimitar os segmentos interacionais relevantes para o alcance dos objetivos. A perspectiva construcionista social foi utilizada como suporte teórico-metodológico e fundamentou a análise dos dados. Os resultados permitiram compreender que as diversas descrições das relações da família com o "transtorno alimentar" permitem delimitar diferentes possibilidades de significar a participação dos familiares no tratamento. Concluiu-se que o grupo pode funcionar como um espaço privilegiado para acompanhar essa produção de sentidos in statu nascendi, permitindo explorar a construção, desconstrução e reconstrução de significados alternativos, que podem enriquecer o horizonte interpretativo de cada participante.
\end{abstract}

Palavras-chave: Transtornos alimentares; família; construcionismo social.

\section{FAMILY PARTICIPATION IN THE TREATMENT OF EATING DISORDERS}

\begin{abstract}
This study aims to understand the meanings about the family participation in the treatment produced in a support group for the families of people diagnosed with anorexia and bulimia. The participants of this study were families attended at a specialized health care service. The data was constituted by the audio recorded registrations of the group session, which were analyzed through the delimitation of its different interactional sections according to this study purposes. The social constructionism approach was used as theoretical and methodological reference and was used to data analysis. The results permitted understanding that the different descriptions about the relation between the family and the treatment can restrict the different possibilities to give meanings to the families' participation in the treatment. We conclude that the group may function as a significant space to observe the meaning production in statu nascendi, making possible to explore the construction and reconstruction of alternative meanings, that may enrich the interpretative possibilities of each participant.
\end{abstract}

Key words: Rating disorders; support group; family; social constructionism..

\section{LA PARTICIPACIÓN DE LA FAMILIA EN EL TRATAMIENTO DE LOS TRASTORNOS ALIMENTARIOS}

\begin{abstract}
RESUMEN. El objetivo de cuesto estudio fue comprender los sentidos sobre la participación de la familia en el tratamiento producido en un grupo de apoyo a los familiares de personas diagnosticadas con anorexia y bulimia. Hicieron parte del estudio familiares atendidos en el contexto de un servicio especializado. El corpus fue constituido por los registros audio grabados de sesiones de grupo, en los cuales se buscó delimitar los segmentos interacciónales relevantes para el alcance del objetivo. El enfoque del construccionismo social fue utilizado como suporte teórico-metodológico y fundamentó el analisis de los datos. Los resultados permitieron comprender que las diversas descripciones sobre las relaciones de la familia con trastornos alimentarios permiten delimitar diferentes posibilidades de significar la participación de los familiares en el tratamiento. Concluye que los grupos pueden funcionar como un espacio privilegiado para acompañar esa producción de sentidos in statu nascendi, permitiendo explorar la construcción, desmanche y reconstrucción de los significados alternativos, que pueden enriquecer los horizontes de interpretación de cada participante.
\end{abstract}

Palabras-clave: Trastornos alimentarios; grupo de apoyo; construccionismo social..

Psicóloga. Professora do Faculdades Integradas Fafibe, Brasil.

\# Psicólogo. Doutor em Psicologia Clínica. Professor do Departamento de Psicologia e Educação da Faculdade de Filosofia, Ciências e Letras de Ribeirão Preto da Universidade de São Paulo, Brasil. 
Considerando-se que a maneira de olhar para a família no contexto da assistência aos chamados "transtornos alimentares" tem se alterado ao longo das últimas décadas, pretende-se neste trabalho discutir diferentes perspectivas a partir das quais podemos entender o posicionamento da família em relação à anorexia e bulimia nervosas e às suas consequências para a construção do lugar de cuidador no tratamento. O termo "transtornos alimentares" será aqui utilizado para referir-se à maneira como o fenômeno alimentar é descrito na atualidade pela Medicina (especialmente no ambiente hospitalar, contexto deste estudo), que considera esses "transtornos" como patologias. A conceituação dos "transtornos alimentares" como patologias é uma das formas possíveis de compreender o fenômeno dentro de determinadas comunidades discursivas, contextualizadas sócio-historicamente, mas não como a única forma de descrição ou a mais útil e válida para todas as populações e contextos de atendimento (Baerveldt \& Voestermans, 1998; Duran, Cashion, Gerber \& Mendez-Ybanez, 2000; Hepworth, 1999; Malson, 1998).

Muitos pesquisadores, na busca pela determinação da etiologia dos "transtornos alimentares, admitem uma etiologia multifatorial que estaria na base dos "transtornos alimentares", com ênfase ora em um ora em outro fator determinante do quadro, dependendo da abordagem teórica (Souza \& Santos, 2006). Entre essas pesquisas, muitas buscaram identificar associações entre a dinâmica familiar e a presença dos sintomas da anorexia e bulimia (Lane, 2002).

Atualmente, as estratégias metodológicas empregadas nesses estudos são questionadas (Fleminger, 2005; Schmidt \& Asen, 2005). Eisler (2005) entende que não existe suporte empírico consistente para a afirmação de que a dinâmica familiar seria um fator predisponente ao aparecimento do "transtorno", uma vez que não é possível afirmar se as características patogênicas nessas famílias aparecem antes do "transtorno" ou se resultam da reorganização de seus membros em face dos sintomas do comportamento alimentar.

Outras críticas referem-se ao fato de muitas das famílias estudadas não se encaixarem estritamente nos modelos teóricos propostos sobre a interação familiar supostamente típica em membros que manifestam esses quadros psicopatológicos (Dare et al, 1995; Gowers \& Bryant-Waugh, 2004). Outro aspecto questionável é que o foco dessas pesquisas considera apenas a percepção dos filhos e filhas, não levando em conta as descrições do fenômeno produzidas por outros membros da família, principalmente os pais. Em relação a este último aspecto, Guttman e Laporte (2002) compararam a avaliação das relações familiares do ponto de vista das filhas com a dos pais, e evidenciaram que há diferença significativa entre esses dois grupos, com a tendência de os pais descreverem suas famílias como mais coesas e flexíveis do que suas filhas.

Os estudos que envolveram o contexto familiar nos "transtornos alimentares" tiveram desdobramentos marcantes no campo da assistência. A dinâmica familiar vista como fator de risco para a anorexia e bulimia contribuiu para a construção de um discurso social patologizante, que frequentemente é imputado às famílias e que, ao culpabilizá-las, contribui para que pais e mães sintam-se ainda mais impotentes ante o caráter insólito dos sintomas de seus filhos (Dodge, Eisler \& Dare, 1995). Um dos riscos desse discurso é cristalizar percepções de irreversibilidade que frequentemente acompanham as vivências dos pais cujos filhos são acometidos por esses "transtornos".

Nos últimos anos tem se consolidado uma vertente teórica segundo a qual os profissionais envolvidos no trabalho com essas famílias devem sair da posição de especialistas no problema, deslocandose para uma posição que valoriza a escuta dos sentidos que as famílias produzem sobre a sua própria experiência de conviver com um(a) filho(a) anoréxico(a) ou bulímico(a). A ênfase tem recaído na escuta dos sentidos daquilo que, para cada família, é constituído como problemático, que pode diferir das explicações propostas pelas teorias que lastreiam as crenças desses profissionais sobre as relações familiares (Fleminger, 2005).

A disponibilidade para ouvir outras vozes presentes nesse contexto dá sustentação teórica para a construção do objetivo deste estudo. O foco passa a ser colocado nos sentidos construídos em conjunto pelos familiares no contexto do tratamento dos chamados "transtornos alimentares", apostando-se na possibilidade de construir sentidos alternativos.

O grupo de apoio psicológico, que reúne as diferentes famílias, tem sido apontado empiricamente pelos profissionais como extremamente benéfico para a obtenção da melhora das condições físicas e emocionais das pessoas com anorexia e bulimia; todavia, embora essa estratégia de atendimento às famílias seja apontada como positiva, sendo vastamente utilizada no contexto brasileiro de atendimento público a esses "transtornos" (Claudino \& Zanella, 2005), a revisão da literatura na área mostra serem escassas publicações que contribuam para a compreensão da sua aplicabilidade no contexto dos "transtornos alimentares", especialmente na assistência aos familiares (APA, 2006; Holtkamp, Herpertz-Dahlman, Vloet \& Hagenah, 2005). 
A isso soma-se o fato de que a aproximação da perspectiva construcionista social à compreensão dos grupos ainda é incipiente (Rasera \& Japur, 2001), o que justifica a proposta de trabalhos que articulem esses dois campos, entendendo-se que essa articulação pode contribuir para ampliar as concepções teóricas existentes sobre a aplicabilidade de grupos na saúde.

$\mathrm{O}$ movimento construcionista-social compreende as práticas grupais como espaços de negociação de significados que criam diferentes realidades relacionais por meio da linguagem (Rasera \& Japur, 2006). Dessa forma, o grupo enquanto estratégia de atendimento terapêutico não segue técnicas específicas. O terapeuta/coordenador deve servir como um facilitador das trocas entre os participantes do grupo. Segundo Rasera e Japur (2006), a composição grupal é negociada entre os participantes, e não definida a priori pelo terapeuta, e a definição do que é o problema e a possibilidade de mudança são construídos por meio da linguagem, considerando-se as interações empreendidas e o contexto de sua produção.

O foco é colocado nas trocas dialógicas, na multiplicidade de sentidos e vozes presentes no grupo e nos discursos sociais que perpassam essas produções (Rasera \& Japur, 2001). O grupo é visto como um recurso conversacional, no qual é possível explorar como a maneira de conversar pode favorecer ou impedir a construção de um contexto terapêutico (Guanaes, 2006), assim ele oferece um contexto fecundo para investigar a maneira como ideias, valores e crenças são construídos pela tradição da comunidade discursiva da qual provêm seus membros, tradição que adquire uma aparência de "realidade" para as pessoas pertencentes àquela comunidade.

Tendo em vista esses pressupostos, o presente estudo tem por objetivo compreender os sentidos produzidos sobre a participação da família no tratamento em um grupo de apoio aos familiares de pessoas diagnosticadas com anorexia e bulimia, atendidas no contexto de um serviço especializado.

\section{PERCURSO METODOLÓGICO}

A abordagem construcionista-social oferece $o$ suporte epistemológico e teórico-metodológico que referenciou esse estudo, principalmente na perspectiva aberta pelos teóricos Kenneth Gergen e Sheila McNamee, escolhidos por serem expoentes representativos desse pensamento no cenário contemporâneo de produção do conhecimento. Segundo Gergen (1994), o construcionismo social busca compreender de que maneira as pessoas geram significados sobre si mesmas e o mundo, entendendo que o próprio ato de significar algo é construtor de realidades. A postura ética e crítica que essa compreensão implica repercute na postura do pesquisador, que vai ser assimilado no processo da produção de sentido, não existindo uma verdade única e irrefutável a ser descoberta ou um ponto de vista privilegiado para o entendimento do objeto escolhido (Anderson \& Goolishian, 1998).

Os sentidos são gerados por meio do diálogo e do discurso e não existem a priori, isto é, antes da investigação a ser feita, mas se constituem no próprio ato de conversar (Anderson \& Goolishian, 1998). Segundo Gergen (1994), o potencial de mudança do significado deriva da ação de outra pessoa na conversação, ou seja, apenas na ação conjunta com outras pessoas podemos entender a função dos sentidos construídos dentro de cada relacionamento.

$O$ universo institucional deste estudo, o Grupo de Assistência em Transtornos Alimentares (GRATA) do Hospital das Clínicas da Faculdade de Medicina de Ribeirão Preto, da Universidade de São Paulo, é um serviço especializado no tratamento dos "transtornos alimentares" $\mathrm{e}$ conta com uma equipe multidisciplinar formada por nutricionistas, psicólogos, médicos, nutrólogos e psiquiatra.

No período em que as sessões grupais foram audiogravadas, 52 pacientes encontravam-se em atendimento regular no serviço, segundo levantamento realizado em maio de 2007. O total de familiares presentes de forma ativa no serviço era de 34 pessoas, uma vez que em algumas famílias mais de um de seus membros participava - em geral o casal parental. No período em apreço a frequência de participação nos atendimentos variou muito entre as famílias.

$\mathrm{O}$ contexto conversacional que sustenta a intervenção e o estudo, o Grupo de Apoio aos Familiares (GAF), consiste em um grupo de apoio psicológico oferecido aos familiares e a outras pessoas significativas da rede social pessoal do paciente que se apresentem ao serviço como acompanhantes nas consultas agendadas e tenham mais de 18 anos. Tratase de um grupo aberto, que ocorre uma vez por semana, no dia de funcionamento do ambulatório. Tem uma hora de duração e tem como objetivo fornecer um espaço de acolhimento e diálogo. Por ocasião da gravação das sessões grupais utilizadas neste estudo a pesquisadora responsável pela investigação participava como observadora.

\section{O contexto ético que dá legitimidade à investigação}

Esta pesquisa contou com a anuência prévia do coordenador do serviço. O projeto foi aprovado pelo Comitê de Ética em Pesquisa da instituição hospitalar. Todos os participantes do grupo selecionado concordaram em participar voluntariamente do estudo 
e formalizaram sua anuência mediante assinatura do Termo de Consentimento Livre e Esclarecido (TCLE).

\section{Participantes}

Estavam presentes na sessão de grupo selecionada: Luma, 34 anos, psicóloga e coordenadora do grupo; Laura, 25 anos, psicóloga, pesquisadora e observadora silente no grupo; Carla, 22 anos, estagiária de Psicologia, também observadora silente; e sete familiares: Salvador, 51 anos, profissional liberal, pai de uma adolescente com anorexia nervosa que estava iniciando o tratamento no serviço; Aurora, 50 anos, esposa de Salvador, dona de casa; Valéria, 62 anos, dona de casa, mãe de uma jovem com anorexia nervosa que era assistida havia 11 anos no serviço e à época se encontrava em estado clínico grave; Adélia, 41 anos, dona de casa, também mãe de uma adolescente com diagnóstico de anorexia nervosa, que frequentava o serviço havia dois anos e cuja filha, em remissão do quadro clínico, encontrava-se em processo de alta; Magali, 46 anos, dona de casa, mãe de uma jovem com bulimia nervosa, que estava iniciando no serviço, e Vicente, 54 anos, profissional autônomo, pai de uma jovem com bulimia nervosa em franca recuperação. Vale ressaltar que, para preservar o anonimato dos participantes, todos os nomes próprios utilizados neste estudo são fictícios.

\section{Procedimento de coleta e análise dos dados}

Durante seis meses os encontros do GAP foram audiogravados em fitas K-7. No início de cada encontro eram esclarecidos a natureza e os objetivos do estudo e a gravação era iniciada apenas se houvesse concordância unânime dos participantes e após firmarem o TCLE. As sessões foram transcritas na íntegra e literalmente. Em uma etapa preliminar de análise foram realizadas leituras sucessivas do material coligido, buscando-se identificar as temáticas emergentes em cada sessão e os segmentos interacionais produzidos na interanimação dialógica, que se mostraram relevantes para o alcance dos objetivos propostos. Foi selecionada por conveniência uma sessão, que se destacou do conjunto como um encontro no qual estiveram fortemente presentes os temas do "papel" que a família desempenha no tratamento.

Para uma análise mais pormenorizada dos sentidos produzidos foi necessário um recorte desse material. Selecionamos o trecho da sessão cuja riqueza polissêmica evidencia-se, sendo um momento de interação significativo para a visualização da negociação de sentidos sobre o tema aqui estudado, apresentando variados posicionamentos, negociações e opiniões sobre a temática da família no tratamento, buscando garantir a pluralidade de pontos de vista dos familiares.

A análise do material coletado foi realizada de acordo com os pressupostos da Teoria Relacional do Sentido (Gergen, 1994; McNamee, 2004), que é o estudo da maneira pela qual as pessoas constroem sentidos juntas. $\mathrm{O}$ foco dessa teoria está no momento interativo, na produção e nas transformações dos significados nas relações, entendendo-se o sentido como social. Não se buscam os sentidos individuais, privados, mas as vastas redes de relações que os participantes atualizam nas trocas dialógicas. (McNamee, 2004), o aspecto performático da linguagem, as palavras, emoções, movimentos, gestos, etc. (Rasera \& Japur, 2007).

Dentro dessa compreensão teórica da produção e negociação de sentidos, utilizou-se também a Teoria do Posicionamento proposta por Harré e Langenhove (1999). O posicionamento refere-se a um conjunto complexo de atributos pessoais por meio dos quais as pessoas são identificadas. Por exemplo, uma pessoa pode ser posicionada ou posicionar-se como poderosa, preocupada, incapaz, sábia, solidária, e assim por diante. Essas posições são estruturadas em função do contexto mais amplo dos direitos, deveres e obrigações que regulam o funcionamento de um determinado grupo social.

\section{Os sentidos produzidos e negociados}

Os resultados serão apresentados por meio de descrições que a pesquisadora construiu a partir de sua leitura dos momentos selecionados do encontro.

O grupo inicia-se com a apresentação de seus participantes. Em seguida começa-se a discutir a participação no grupo, tecendo-se sentidos para a presença do familiar naquele espaço. Salvador se engaja na construção de uma narrativa na qual ele recorre a momentos significativos de sua história de vida:

Salvador: No meu serviço tem criança (fala com um sorriso no rosto) que pergunta:"Você é caçula, do meio ou adulto?”. Todo mundo sabe que eu sou caçula apesar dos 52 anos, (risos) mas, na verdade, eu me sinto assim... muito contente de participar desse grupo. Desde a primeira vez eu já esperava, pra ser sincero, assim, algo bom, porque, modéstia à parte falando, eu sou muito otimista. Tanto é que não quero dar testemunho da minha vida nem nada, mas como sou nordestino (...) minha família sempre teve dificuldade e eu tive que me virar e foi participações assim, com outras pessoas, que me ajudou muito pra mim tar 
aqui hoje. E modéstia à parte assim... contente e um pouco sadio. (...) Aqui é um grupo que a gente colhe o que planta. Eu vejo como muito positivo essas participações $e$ tô muito contente também, além de verificar assim que a Michele (sua filha) já tá colhendo.

Nota-se, no segmento destacado, que se apresenta o Salvador nordestino, caçula de vários irmãos, que desde muito antes de sua entrada no grupo já esperava partilhar "algo de bom" com os demais familiares. As razões apontadas para trazer para o grupo essa crença esperançosa está na autodescrição que ele produz: o fato de ser "muito otimista", por ter tido que "se virar nessa vida" e por ter podido se beneficiar anteriormente de outras participações em contextos de ajuda semelhantes. Considerando-se a continuação dessa conversa, pode-se perceber a maneira como essa fala repercutiu nos demais participantes:

Valéria (dirigindo-se a Salvador): É uma só? Salvador: Uma filha só? É. Valéria: Então não tem irmão pra brigar, né? Salvador: (Ri) Não, mas a família é muito grande e, modéstia à parte, é um pouco... de estarem juntos assim, entendeu? Não tem assim, por exemplo, uma semana que nós não nos encontremos.

Valéria busca relativizar o sentido trazido por Salvador de que é a atitude de enfrentamento da situação que leva a um resultado positivo no tratamento, afirmando que isso só é possível porque Salvador tem apenas uma filha, portanto ela "não tem irmãos para brigar" - lembrando aqui que Valéria tem três filhos - um homem e duas mulheres.

A afirmação de Salvador de que a situação positiva é alcançada pela posição obstinada de enfrentamento da situação e pela "colheita do que de bom fora plantado" parece levar Valéria a ter que se posicionar em defesa de "seu caso", uma vez que não vive uma situação positiva quanto ao resultado do tratamento da filha, que vinha evoluindo desfavoravelmente. Assim, uma vez aceita a argumentação de Salvador, ela não teria enfrentado adequadamente a situação de adoecimento da filha.

$\mathrm{O}$ riso de Salvador e o uso reiterado da expressão "modéstia à parte" parecem confirmar a hipótese acima, com uma aparente tentativa de amenizar sua eventual discordância em relação a Valéria. Ao mesmo tempo, Salvador parece refutar a justificativa de Valéria de que seria simplesmente o fato de ter apenas uma filha o que o teria conduzido ao bom resultado "colhido". Afirma que, embora não tenha outros filhos, é oriundo de uma "família muito grande", portanto haveria a possibilidade de se produzir discórdia ou mesmo brigas.

Chama a atenção a fala de Salvador de que se sente "contente e um pouco sadio". O sentido do grupo como um espaço para o tratamento da família aparece de maneira frequente nas sessões desse grupo de apoio, como notado pela pesquisadora ao longo do período de observação. Esse sentido associa-se à ideia de que a família também estaria "adoecida", por isso precisaria de tratamento e não estaria completamente "sadia". Salvador traz um sentido que se contrapõe a essa construção da família "doente", afirmando que se sente "um pouco sadio" e que, mesmo sendo iniciante no grupo, já se sente como alguém que está bem.

Após Salvador afirmar que, nos próximos encontros, ele e a mulher iriam se revezar para irem ao grupo, sua esposa Aurora questiona: "Esse problema que ela tem, essa doença, ela só vai se curar se a gente participar do grupo e ela lá também? Ou quando a gente percebe, ela já está curada?"

Pode-se entender a pergunta de Aurora como um confronto com os sentidos sobre a participação no grupo produzidos até então. Sua questão evidencia a multiplicidade de perspectivas possíveis sobre o grupo de apoio. Aurora procura saber de que maneira o grupo poderia ajudar. A existência de uma mãe que está há mais de uma década frequentando o serviço em busca da cura da filha coloca em xeque a pretensão da imediaticidade da cura. Quando essa perspectiva um tanto idealizada não se concretiza, como legitimar a função no grupo?

A coordenadora responde a Aurora:

Luma: Vamos deixar para o grupo responder. Eu acho que isso é uma vivência, né? Não é um exame que vai dizer: "Olha, curado!", "Não tá curado", "O caminho é esse, não, é esse!”. Acho que a vivência do grupo pode enriquecer, comunicar um pouco da experiência de vocês!

Luma pontua essa dúvida, dando consistência ao ceticismo que, de um modo sub-reptício, permeava algumas falas até então. Isso abre para os demais participantes a possibilidade de se confrontarem diretamente com a questão e assim debaterem os diversos sentidos aí implicados. Valéria afirma na sequência: "Porque tem que ter a nutróloga, tem que ter a psiquiatra, a psicoterapia também, né? Tudo isso ajuda, né? Agora eu não sei se sua filha já parou com a medicação ou não. A minha faz uso".

Essa fala coloca apenas nos profissionais a possibilidade de promoção dos cuidados de seus filhos 
adoecidos. Os recursos são identificados apenas na equipe de saúde.

Salvador responde à pergunta de Valéria sobre a medicação afirmando a importância dos profissionais, mas reafirma o papel fundamental da família na "detecção do problema" para que ele não fique "aprofundado":

Salvador: As consultas ela vai continuar, né? Até a hora que a própria médica achar que ela deve, mas é um remedinho, é ácido fólico, não chega a tomar medicamento assim... pesado, não. Porque pelo jeito, graças a Deus nós tivemos assim... a sorte de detectar o problema e nos comprometer a ir atrás. Não deixou ficar muito. Porque eu vejo assim (...) tem os próprios pais - a gente já percebeu - que não admite que é doença, não é verdade? Eu não sei, mas só da pessoa achar isso ele já tá precisando de se cuidar há muito tempo. (...) Porque aí vem aquele ponto que a senhora tá falando, assim, sua filha há bastante tempo tal, suas dificuldades. A gente vê que é bastante aprofundado, né? Eu tenho, graças a Deus, eu vejo muitos sinais positivos na Michele (filha): já melhorou bem, não chegou a ficar em estado grave... de jeito nenhum, essa preocupação de estar junto.

Segundo Salvador, o fato de estar ali significava que a família fora capaz de "detectar" o problema e ir atrás do tratamento, o que ajudara a filha a não ficar tão grave a ponto de ter que tomar "medicamento pesado". Ele coloca na família a possibilidade de estar alerta e, tendo adquirindo a consciência do que está se passando, assumir uma posição ativa. Afirma perceber que a falta desse comprometimento decorre do fato de a família não "admitir que é uma doença", o que evidenciaria a necessidade de a própria família ser submetida a tratamento.

Esse momento interativo da sessão coloca de um lado Valéria, cuja filha estava necessitando de diversos suportes de cuidado, entre eles a medicação, e a filha do casal formado por Salvador e Aurora, que naquele momento não necessitava de "tanto" cuidado. $\mathrm{Na}$ negociação do que provavelmente levaria à existência de diferenças na gravidade do quadro sintomatológico dos filhos, temos o sentido produzido da severidade dos sintomas relacionados à postura negligente da família de não buscar logo ajuda, o que implicaria que a própria organização familiar estaria "adoecida" por não ter percebido a tempo que estava diante de uma "doença", passo essencial para a busca de ajuda especializada.
A coordenadora intervém e interrompe esse diálogo:

Luma (interrompendo): $E$ aí, em que situação vocês acham que o grupo entra como parte do tratamento? (...) Acho que essa é a dúvida da Aurora, né? Assim, do quanto esse grupo pode ajudar no tratamento, né? Que papel é esse que esse grupo tem?

Vicente, em resposta à questão formulada por Luma, traz o aporte de um sentido muito parecido ao construído por Salvador:

Vicente: Porque acho que são dois
pacientes, pacientes pra lá e nós aqui
também. Porque, na verdade, a gente
também fica... desvia um pouquinho daquilo
que seria a normalidade, né? (...) Então
acho que aqui as pessoas vão se habilitar a
entender, compreender a situação daquelas
pessoas, dos filhos.

Para Vicente, a família também estaria "adoecida", "desviada da normalidade", portanto precisaria ser tratada pelo serviço. O grupo seria o espaço para a família se habilitar a "compreender a situação dos filhos". Além disso, favoreceria a percepção "exata" de que os familiares "estão diante de um problema", uma "doença", e que o papel da família é mais fundamental que o do médico, por ser um "problema psíquico" e não físico. Esse papel relacionar-se-ia à necessidade de reorganização da família para possibilitar a recuperação do paciente. Essa reestruturação seria responsável por " $60 \%$ da melhora":

Vicente: E que cada um de nós tem a percepção exata que tá diante de um problema, um problema psíquico, lógico, mas tá diante de um problema. Eu acho que os pais, principalmente os pais, têm uma participação - imagino eu - na recuperação dos filhos, das filhas, fundamental. Acho que mais que, de repente, até a participação do médico (...) pra esse tipo de doença, como é psíquica. A família deve estar estruturada no que as pessoas estão aprendendo (...) Eu acho que é um passo de $60 \%$ na recuperação.

Nessa altura do encontro fica clara a diferença do significado assumido pela família no tratamento nas falas de Vicente e de Salvador. Para Salvador, a família só está "doente" enquanto não reconhece que é 
um "problema". O grupo seria espaço de responsabilização e agente promotor da melhora, e não de tratamento da família. Já Vicente parece perceber que a presença no lar desse "problema psíquico" é sugestiva do "desvio da normalidade" da própria família, mas não esclarece se como causa ou consequência da "doença".

Para Vicente, esse cuidado da família é um aprendizado de como viver "em torno" da filha, apoiando-a discretamente, sem que ela o perceba, de modo que ela leve uma "vida normal". Ele reconhece que esse apoio oferecido à filha possibilitou a sua melhora:

$\mathrm{Na}$ medida que eu fui aprendendo (...) vivendo em torno dela, mas sem ela perceber também. Estando com o apoio, mas sem percepção também. Uma coisa quase normal, a vida normal. A Cíntia (filha) melhorou muito.

Após essas falas Valéria volta a se pronunciar e conta que já houve um momento no qual não colocou em dúvida se aquilo que a filha tinha era realmente uma "doença". Afirma que o tempo em que ficou sem acreditar na "doença" se deu em função da dificuldade de admitir que a filha, idealizada como "perfeita", estivesse "nessa situação" (de adoecimento):

Você passa muito tempo não acreditando que a pessoa é doente. Então você vai aprender que é a doença, é uma doença, porque antes a gente não aceita: Como? Meu filho era perfeito e está nessa situação?

$\mathrm{Na}$ fala de Salvador, essas seriam as pessoas que estariam precisando de tratamento. A posição assumida por Valéria a força a encontrar uma justificativa pelo longo tempo que se passou até que ela percebesse o que estava acontecendo com a filha. Essa dificuldade de reconhecimento e aceitação da "doença" da filha poderia ser interpretada pelo grupo, a partir dos sentidos produzidos até então (principalmente com a fala de Salvador), como possível "negligência" por parte de Valéria em relação ao sofrimento da filha.

Posteriormente, Valéria consegue se reposicionar, ao interpor uma narrativa na qual se descreve como mãe zelosa e cuidadora, que pôde mudar suas atitudes em relação à filha e, com isso, aprendeu uma melhor maneira de agir diante de seu comportamento:

A gente aprende a paciência, que é o principal. Não em exagero, porque a minha era em excesso. (...) Eu aprendi muitas coisas que eu fazia e não faço mais (...) agora já tenho o controle da situação.

Com a produção dessa narrativa, em oposição à da mãe negligente e insensível aos tormentos da filha, produzida anteriormente, Valéria parece buscar garantir sua aceitação no grupo, ao mesmo tempo em que reconstitui sua autoestima, esforçando-se por oferecer uma nova narrativa de si, na qual busca se reconhecer em uma descrição menos mortificante.

\section{DISCUSSÃO}

Quando o contexto se mostra favorável ao engajamento na roda de conversações, a trama das interações fomenta algumas perguntas: quem é quem no grupo? Qual o lugar a mim designado? Sou o caçula iniciante que não tenho nada a oferecer e nada sei sobre a doença, ou sou o adulto que já está habilitado e fortalecido para lidar com a situação adversa de maneira madura?

Salvador parece buscar um sentido ampliado de sua participação no grupo, como alguém que também pode ofertar ajuda, ainda que se reconheça na condição de iniciante ("filho caçula" do grupo). Esse participante busca romper com o sentido fixo que parecia ter sido construído sobre o papel do novato no grupo - como aquele que apenas espera receber ajuda - confrontando os sentidos anteriores das diferenças existentes entre os participantes e buscando com esse recurso demarcar que os diferentes posicionamentos levam a diferentes ações no grupo.

Para Gergen (1994), o uso que se faz das narrativas vai depender de suas funções nas relações. Em sua narrativa de conquista de resultados positivos no tratamento da filha, Salvador parece negociar a possibilidade de também ser visto como alguém que tem histórias positivas, embora tente em vários momentos diluir essa posição de quem se sente um pai exemplar - que poderia talvez ser interpretada por alguns como soberba - recorrendo a expressões como: "modéstia à parte”, "apoio discreto", ou "não quero dar testemunho da minha vida nem nada”. Ao se descrecer dessa maneira, ele pode buscar uma posição mais ativa no grupo, mas inadvertidamente acaba por construir um julgamento depreciativo do papel de Valéria enquanto cuidadora materna.

Salvador pôde apropriar-se do espaço grupal, entendendo sua participação como independente da participação da filha. Conforme sustenta McNamee (2004), o confronto de diferentes sentidos abre espaço para o aparecimento de novas descrições. Nessas descrições alternativas, o que é tido como certo 
depende do contexto das relações que se estabelecem dentro de determinadas racionalidades. Ora, se não é unicamente em função do paciente identificado, então para que serve o grupo? Esse questionamento materializa-se formidavelmente nessa sessão grupal, trazendo desdobramentos em termos da ampliação dos sentidos possíveis de serem negociados a respeito da participação no grupo. Até que se desdobram dois sentidos para essa participação, presentes no segundo fragmento analisado: participar para tratar a família também "adoecida", ou participar para aproximar-se de outras pessoas sensibilizadas pela mesma dor?

A família, no sentido oferecido quando se considera que ela pode ser um "outro paciente" que precisa de cuidados, é destituída de seu saber sobre a experiência pela qual está passando. Além de desconhecer o que se passa, não teria a habilidade de reconhecer a "doença" e teria que contar com o conhecimento especializado do profissional ou dos familiares "mais velhos no grupo" para aprender a lidar com a situação que a desconcerta, lançando-a na alienação.

O grupo, visto como lugar de tratamento da "patologia" dos familiares - ou, mais precisamente, dos vínculos familiares - remete ao discurso da psicopatogênese familiar encontrado de forma abundante na literatura produzida sobre os "transtornos alimentares" (Souza \& Santos, 2007). Esse discurso científico defende e se sustenta na convicção de que a dinâmica familiar seria o grande fator etiológico responsável pelo adoecimento psíquico dos pacientes com anorexia e bulimia (Eisler, 2005). Consideramos que tal discurso ainda hoje corresponde a uma das linhas de força na clínica dos transtornos alimentares, o que inspira a construção de concepções naturalizadoras que desembocam na culpabilização dos pais. Esse sentido precisa ser meticulosamente desconstruído pelo coordenador de grupo, uma vez que fortalece posicionamentos que contribuem para fixar os pais em um lugar de impotência e sofrimento.

A linguagem do senso comum é permeada pelos repertórios interpretativos (termos utilizados, lugarescomuns, descrições e figuras de linguagem que eventualmente funcionam como clichês) produzidos no domínio dos saberes científicos, dentre outros saberes formalizados e socialmente construídos (Spink \& Medrado, 2000). No GAF percebemos que o discurso da psicopatogênese familiar está presente nos repertórios disponíveis às pessoas para entabularem suas práticas discursivas no grupo, servindo às vezes como indicador da estabilidade (consenso) e da dinâmica (polissemia) presentes nessas comunicações e na apropriação que é feita desse discurso (Spink \&
Medrado, 2000). As práticas discursivas podem ser definidas como as maneiras através das quais as pessoas produzem sentido e se posicionam nas relações (Spink \& Medrado, 2000).

É preciso submeter ao escrutínio crítico do grupo a reprodução acrítica dessas formulações discursivas, que funcionam muitas vezes como repertórios interpretativos que as pessoas utilizam automaticamente diante das situações que desconhecem. O enfrentamento de um fenômeno complexo como o "transtorno alimentar", cuja etiopatogenia ainda se encontra mergulhada em incertezas e indeterminações, desafiando o conhecimento científico hegemônico, é um "prato cheio" para especulações de todo o tipo, já que o enigma do "transtorno" não cessa de interpelar o ser humano, com sua lacuna de sentidos. Afinal, o que é da ordem do incerto e do desconhecido faz um apelo incessante à produção de significação, buscando-se pela via da atribuição de sentidos reduzir a tensão permanente e ameaçadora despertada por algo que não se conhece.

$\mathrm{Na}$ interação grupal, Valéria, Aurora e Salvador parecem se defender do potencial estigmatizante desse discurso, buscando justificar suas ações, que poderiam ser interpretadas como marcadores de possível negligência ou culpa pela "doença". Salvador afirma ter buscado tratamento tão logo percebeu o problema, "não deixando ficar tão grave"; Valéria afirma que é difícil reconhecer a "doença", porque "os pacientes a escondem"; e Vicente acredita que a família também está "adoecida", pois tem dificuldade de perceber que está "diante de um problema".

$\mathrm{Na}$ legitimação desse discurso, a autoridade sobre as práticas de cuidado dos filhos fica depositada nas mãos dos profissionais do serviço, como afirma Valéria em um primeiro momento; entretanto podemos perceber uma renegociação desse primeiro sentido, com o questionamento de qual seria a "porcentagem" do papel da família na melhora do filho - ou seja, qual a parte que lhe caberia desse "latifúndio" denominado "transtorno alimentar".

Para Salvador, a intervenção da família é fundamental no reconhecimento do "transtorno alimentar" e na tomada de providências para combatêlo. Podemos perceber aqui o delineamento de uma nova maneira de se construir a posição da família na ação de cuidado com os filhos, uma posição mais ativa, de tomada de consciência e confrontação com a situação adversa. $\mathrm{Na}$ fala de Vicente esse sentido é clareado com a sua percepção de que o papel da família no tratamento é mais importante do que a própria intervenção dos profissionais. 
Os valores presentes nas diferentes maneiras de descrever o papel da família no tratamento relacionam-se diretamente à construção da maneira de se perceber e interagir dentro do grupo. $\mathrm{O}$ discurso da psicopatogênese familiar traz como uma de suas consequências a construção da culpa da família pela "doença" do filho, portanto, a diferença na gravidade dos sintomas entre os filhos levaria à diferença no "grau" de culpabilização dos pais. Há uma ênfase na atribuição de culpa, o que é bem diferente de admissão de responsabilidade, ou melhor, da postura de corresponsabilização pelos cuidados necessários diante do "transtorno mental" de um filho. Considerando a crítica que o movimento construcionista faz a essa visão estigmatizante da família, entendemos que o coordenador de grupo pode ajudar os familiares a revisarem as crenças que são sustentadas pelos discursos circulantes no grupo, tais como o da família também "adoecida", "desestruturada", "desviada da normalidade" e necessitada de "se habilitar", que dão origem a posicionamentos que dificultam o engajamento no tratamento e só contribuem para perpetuar as condições geradoras de sofrimento.

Quando os participantes utilizam determinadas terminologias que são consagradas pelo discurso biomédico hegemônico e postas em relevo pelo ambiente hospitalar no qual o grupo se desenvolve, tais como "paciente", "gravidade", "doença", "cura", "normalidade", "família desestruturada", podem estar construindo relações de estigmatização dentro do próprio grupo, ratificando noções amplamente difundidas de falha, déficit, inabilidade ou incapacidade pessoal (Gergen \& McNamee, 2000) no trato com a "doença". O sistema de valores implícitos no discurso diagnóstico leva os participantes a buscarem se diferenciar uns dos outros comparando a gravidade da "doença" dos filhos, como se estivessem perscrutando a extensão de sua própria "culpa", ao interrogarem qual seria a suposta medida de seu próprio "fracasso" e "incompetência" na criação dos filhos. Encontrar meios que permitam sair desse discurso autorrecriminatório e do sentenciamento sumário é um desafio a ser enfrentado no coletivo grupal.

Certas concepções científicas acabam validando essas crenças derrisórias, contribuindo para cristalizar uma visão de pais como produtores da "insanidade" de seus filhos. Essas concepções são derivadas do conhecimento psicanalítico e psiquiátrico, que influenciou fortemente o processo histórico de construção e naturalização da noção de "transtornos alimentares".
A propósito, Lane (2002) chega a falar em certa "mãe-aranha", o que lembra de certo modo o construto de mãe esquizofrenogênica que esteve muito em voga nos idos de 1960.

Nesse cenário torna-se difícil manter a confiança desses familiares na possibilidade de tirarem partido do fato de se unirem e continuarem juntos, mantendo os laços que alimentam continuamente essa trama/rede vincular que lhes permite apoiarem-se uns aos outros, buscando a resolução de suas dificuldades pessoais, como sugere a proposta do grupo de apoio (Bechelli \& Santos, 2001). Nessa vertente, o grupo de familiares emerge como um espaço que permite não apenas a apropriação de saberes e fazeres relacionados aos modos de os familiares conviverem com "o transtorno alimentar", mas, sobretudo, como uma arena de construção permanente de novos sentidos possíveis sobre o processo saúde-doença e de novas redes de apoio social.

Tan e Moghaddam (1999) entendem que os movimentos de diferenciação (ou discriminação), presentes nas diversas relações humanas, refletem o poder persuasivo e cristalizador das histórias que as pessoas contam sobre si mesmas. A aceitação de novas histórias e posições dependerá das regras, deveres e obrigações construídos para cada pessoa dentro da história do grupo, assim como da capacidade do grupo de ser compreensivo em relação às necessidades que cada um apresenta de ressignificação de sua própria história.

\section{CONSIDERAÇÕES FINAIS}

Este estudo permitiu compreender de que maneira os diversos discursos sobre a família são partilhados e negociados em um grupo de apoio aos familiares de pessoas diagnosticadas com "transtornos alimentares". Possibilitou entender de que modo as descrições sobre o papel da família no contexto do tratamento constroem diferentes possibilidades de significar a participação dos familiares, que favorecem algumas maneiras de pensar e agir e ao mesmo tempo limitam outras.

Vimos, assim, que esse grupo pode funcionar como um espaço privilegiado para acompanhar a produção de sentidos in statu nascendi, permitindo explorar as possibilidades inusitadas de construção e reconstrução de significados alternativos, que podem enriquecer o horizonte interpretativo de cada participante. Na medida em que vão se produzindo relatos instigantes, que se enriquecem ainda mais ao serem compartilhados, formam-se redes que 
possibilitam outros caminhos para construir o apoio social e novas maneiras de lidar com as adversidades.

\section{REFERÊNCIAS}

American Psychiatric Association. (2006). Practice guideline for the treatment of patients with eating disorders. Washington, DC: American Psychiatric Association.

Anderson, H. \& Goolishian, H. A. (1998). O cliente é o especialista: A abordagem terapêutica do não-saber (C. O. Dornelles, Trad.). Em S. McNamee \& K. J. Gergen (Eds.), A terapia como construção social (pp. 34-50). Porto Alegre, RS: Artes Médicas.

Baerveldt, C. \& Voerstermans, P. (1998). The body as a selfing device: The case of anorexia nervosa. In H. J. Stam (Ed.), The body and psychology (pp. 161-181). London: Sage Publications.

Bechelli, L. P. C. \& Santos, M. A. (2001). Psicoterapia de grupo: Noções básicas. Ribeirão Preto, SP: Legis Summa.

Claudino, A. M. \& Zanella, M. T. (2005). Transtornos alimentares e obesidade. São Paulo, SP: Manole.

Dare, C., Eisler, I., Colahan, M., Crowther, C., Senior, R. \& Asen, E. (1995). The listening heart and the chi square: Clinical and empirical perceptions in the family therapy of anorexia nervosa. Journal of Family Therapy, 17, 31-57.

Dodge, E., Matthew, H., Eisler, I. \& Dare, C. (1995). Family therapy for bulimia nervosa in adolescents: An exploratory study. Journal of Family Therapy, 17, 59-77.

Duran, T., Cashion, L. B., Gerber, T. A., \& Mendez-Ibanez, G. J. (2000). Social constructionism and eating disorders: Relinquishing labels and embracing personal stories. Journal of Systemic Therapies, 17(2), 23-42.

Eisler, I. (2005). The empirical and theoretical base of family therapy and multiple family day therapy for adolescent anorexia nervosa. Journal of Family Therapy, 27, 104-131.

Fleminger, S. (2005). A model for the treatment of eating disorders of adolescents in a specialized centre in The Netherlands. Journal of Family Therapy, 27, 147-157.

Gergen, K. J. (1994). Realities and relationships: Soundings in social construction. Cambridge: Harvard University Press.

Gergen, K. J., \& McNamee, S. (2000). From disordering discourse to transformative dialogue. In R. Neimeyer \& J. D. Raskin (Eds.), The construction of disorder (pp. 333-349). Washington, D.C.: American Psychological Association.

Gowers, S. \& Bryant-Waugh, R. (2004). Management of child and adolescent eating disorders: The current evidence base and future directions. Journal of Child Psychology and Psychiatry and Allied Disciplines, 45, 63-83.

Guanaes, C. (2006). A construção da mudança em terapia de grupo: Um enfoque construcionista social. São Paulo, SP: Vetor.

Guttman, H. A. \& Laporte, L. (2002). Family members' retrospective perceptions of intrafamilial relationships. Contemporary Family Therapy, 24, 505-521.
Harré, R. \& Van Langenhove, L. (1999). Reflexive positioning: Autobiography. In R. Harré \& L. Langenhove (Eds.), Positioning theory (pp. 60-73). Oxford: Blackwell.

Hepworth, J. (1999). The social construction of anorexia nervosa. London: Sage Publications.

Holtkamp, K., Herpertz-Dahlmann, B., Vloet, T. \& Hagenah, U. (2005). Group psychoeducation for parents of adolescents with eating disorders: The Aachen Program. Eating Disorders, 13, 381-390.

Lane, R. C. (2002). Anorexia, masochism, self-mutilation, and autoerotism: The spider mother. Psychoanalytic Review, 89, 101123.

Malson, H. (1998). The thin woman: Feminism, post-structuralism, and the social psychology of anorexia nervosa. London: Routledge.

McNamee, S. (2004). Social construction as practical theory: Lessons for practice and reflection in psychotherapy. In D. Pare \& G. Larner (Eds.), Collaborative practice in psychology and therapy (pp. 9-22). New York: Haworth Press.

Rasera, E. \& Japur, M. (2001). Contribuições do pensamento construcionista para o estudo da prática grupal. Psicologia, Reflexão e Crítica, 14(1), 201-109.

Rasera, E. \& Japur, M. (2006). Sobre a preparação e a composição em terapia de grupo: Desconstruções construcionistas sociais. Psicologia, Reflexão e Crítica, 19(1), 131-141.

Rasera, E. \& Japur, M. (2007). Grupo como construção social: Aproximações entre construcionismo social e terapia de grupo. São Paulo, SP; Vetor.

Schmidt, U. \& Asen, E. (2005). Does multi-family day treatment hit the spot that other treatments cannot reach? [Editorial]. Journal of Family Therapy, 27, 101-103.

Souza, L. V., \& Santos, M. A. (2006). A família e os transtornos alimentares. Medicina (Ribeirão Preto), 39, 403-409.

Souza, L. V. \& Santos, M. A. (2007). Anorexia e bulimia: Conversando com as famílias. São Paulo: Vetor.

Spink, M. J. \& Medrado, B. (2000). Produção de sentidos no cotidiano: Uma abordagem teórico-metodológica para análise das práticas discursivas. Em M. J. Spink (Org.), Práticas discursivas e produção de sentidos no cotidiano: Aproximações teóricas e metodológicas (pp. 93-133). São Paulo: Cortez.

Tan, S. L. \& Moghaddam, F. M. (1999). Positioning in intergroup relations. In R. Harré \& L. Langenhove (Eds.), Positioning theory (pp. 178-194). Oxford: Blackwell.

Recebido em 14/05/2008 Aceito em 06/02/2009
Endereço para correspondência:
Laura Vilela e Souza. Av. Bandeirantes, 3900, CEP 14040-901, Ribeirão Preto-SP, Brasil. E-mail: lacake@uol.com.br. 